\title{
Contemplative insight as an opinion conflict and a search for meaning in the context of innovative elements of the revolution industry 4.0
}

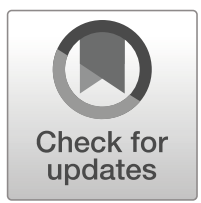

\author{
Stefan Chudy ${ }^{1} \cdot$ Pavel Neumeister $^{1} \cdot$ Iva Koribska $^{1}$ (D) Martin Strouhal $^{2}$. \\ Denisa Selicka ${ }^{3}$
}

Received: 23 April 2020 / Accepted: 7 July 2020 / Published online: 14 July 2020

(C) The Author(s) 2020

\begin{abstract}
The aim of this study is to present an insight into the issue of technology and innovation reform with an emphasis on their integration into the social sciences. Using discourse analysis, we have reconstructed the basic elements of reforms and their reflections into a theory that changes not only in terms of content and terminology, but mainly in terms of logic and rationalization of new paradigms. These changes are reflected in the transformation of society, bringing new challenges and defining the relationship between innovation and society. An important outcome of the analysis is pointing out the change in values in society and their reflection in the form of challenges that respect changes in the labor market and educational policies of the various educational institutions.
\end{abstract}

Keywords Discurse analysis $\cdot$ Industry $4.0 \cdot$ Innovation $\cdot$ Paradigm $\cdot$ Social changes

Iva Koribska

iva.koribska@upol.cz

Stefan Chudy

stefan.chudy@upol.cz

Pavel Neumeister

pavel.neumeister@upol.cz

Martin Strouhal

martin.strouhal@ff.cuni.cz

Denisa Selicka

dselicka@ukf.sk

1 Faculty of Education, Institute of Education and Social Studies, Palacký University in Olomouc, Olomouc, Czech Republic

2 Department of Education, Faculty of Arts, Charles University in Prague, Prague, Czech Republic

3 Department of Sociology, Faculty of Arts, Constantine the Philosopher University in Nitra, Nitra, Slovak Republic 


\section{Birth of a new myth (from legend to myth and back)}

The time we live in, according to current scientific experts in all technical, scientific and economic disciplines, is a time full of changes and revolutions in technology. We are standing on the threshold of the era defined by these groups as a technological revolution that will change fundamentally the world we live in, work or communicate. They draw attention to the complexity of changes in the transformation of society, so important to humanity. They swear in the name of concepts such as complexity, integration, global basis, changes in the public and private sector, interference with academic and civil social groups.

These experts perceive the reform or rather transformation in the light of simplified vision of history as a continuation of industrial revolutions. Like any other part of history predetermining and defining man and his place in the society, the revolution called Industry 4.0 integrates this historical definition line by in its own way. It comes from a simplified description of the linear view of the history discourse of technique. It reflects the description of events that use one-way insight into changes in human evolution. This transcript consists of a statement about the revolution using steam (1st industrial revolution) and production mechanization, using electricity, belt and series production (2nd industrial revolution), applying electronics and information technology to automate production (3rd industrial revolution). 4th industrial revolution is defined as a follow-up to the previous one and is called a digital revolution. The definition and its progress is visible in the merger of technologies, the wiping of the boundaries between the digital, physical and biological realms. Reasons such as speed, range and impact of systems are also specified. Border wiping is described by the rate of discoveries without historical precedent. ${ }^{1}$

However, simplification in terms of moving from linear to exponential progress is inadequate, flat and highly questionable. The speed of discovering and interfering with all areas of human activity is mainly due to the transformation and fragmentation of the disciplines into segments that do not explore the nature of the phenomenon from an interdisciplinary perspective, but mainly from the view of individual minimalist science areas. $^{2}$ These disciplines define this problem and create new linguistic and logical hiatuses of long-defined terms and categories, creating new metatheories and metametatheories of metatheories. The supportive means of the emerging meta-language are the results of digitization related to people (social networks, e-courses, online life, etc.), the combination of data repositories and access to knowledge, as an unlimited category of knowledge. This approach is based on the analogous perception of binarity, which manifests itself in a tier and simplified solution to the social situations. A pre-prepared (programmed) environment requires simple solutions that will "be cool" and fit into the cliché answers (Eco, 2002). ${ }^{3}$

Creating a picture of phenomena and situations in the world in the form of precisely organized categories that follow a strict and clearly predetermined causality (Skinner, 2000). This mythical phenomenon of the revolution is manifested in the definition of present-day challenges, which are defined by market variability, shortening of the production cycle and

\footnotetext{
${ }^{1}$ Is it really true? It was not like that in any other defined era of revolutions?

${ }^{2}$ Examples include biotechnology, nanotechnology, socioeconomics and other science disciplines.

${ }^{3}$ In the sense of U. Eco - medieval thinking. More in Eco, Umberto. Art and Beauty in the Middle Ages.

Translated by Hugh Bredin. New Haven: Yale University Press, 1986.
} 
by the global influence of the supplier and consumer. In this environment, the production is decreasing and the flexibility of business trends, cheaper production and flexibility is emphasized. A similar situation can be seen in the field of education. An online course is an example. The content of the course is given by its nature, but it is also defined by a simple goal, according to a template (e.g. educational goals according to Bloom's taxonomy). The outputs (competencies) are clearly specified and the whole process takes place in a precisely and clearly defined and programmed environment. The solutions and the way to the "successful" completion and the acquisition of the required output competency is causally analogous to the clearly defined outcome and solutions set out in the education system. In many ${ }^{4}$ of the defined limits set by the organizer and programmed by algorithms, a failure element in the form of a new solution or error is not allowed. An individual coming up with a new solution or working with an error (Dörner, 1989) s $^{5}$ is dependent, thanks to a program algorithm on another functional solution and successful completion of a pre-set goal. The limitations of a given situation within a given framework do not force a person to resort to failure or to work with various components of creativity. ${ }^{6}$ Analogous thinking requires graduates to be graded and taxonomized in the sense of being successful, not addressing the essence of the education. It is not intended to change the status quo in terms of status qou ante and to understand the changes in the world and society. This is to some extent caused by the digitization leading to smart city, smart factory and smart world models.

\subsection{Creating new paradigms as an innovation attempt (Uroboros on its halfway and supermarket robbery)}

The challenges of the current society from the perspective of Industry 4.0 are subject to the intensity of changes in the opportunities they produce. World Industry 4.0 is built on the idea of mutual communication and collaboration in the meaning of logistics systems, information sharing machines. This effort includes networking that appears in professional literature as a paradigm - connectivism (Kop \& Hill 2008). ${ }^{7}$ This paradigm is presented in learning theories (Downes, 2010; Siemens, 2004) ${ }^{8}$ as an innovative element based on behaviorism, cognitivism and constructivism. Many representatives of science and technology field emphasize its principles such as flexibility, creating a sense of interconnection of thoughts and emotions, and point to an exponentially increasing amount of information. The goal is increased activity "to do something", linking special nodes and sources of information. Strengthening and maintaining these nodes creates a precondition for better learning and results. A course environment, a

\footnotetext{
${ }^{4}$ Not all

${ }^{5}$ Failure is perceived in this case as positive phenomenon of creativity development. See more Dörner, D. (1989). The logic of failure. New York, NY: Holt (cf. German edition, Die Logik des Mißlingens, 1993).

${ }^{6}$ Flexibility, fluency etc. See more Skinner, B. F. (1953). Science and human behavior. New York: Macmillan.

${ }^{7}$ Connectivism - as an example of pseudo-paradigmatic conception of thinking. For example: Rita Kop, Adrian Hill. Connectivism: Learning theory of the future or vestige of the past? In "The International Review of Research in Open and Distance Learning”, Vol 9, No 3 (2008), ISSN 1492-3831.

${ }^{8}$ See also Siemens, G. (2005). Connectivism: A learning theory for the digital age. International Journal of Instructional Technology and Distance Learning, 2(1), 3-10., Downes, S. (2010). New technology supporting informal learning. Journal of Emerging Technologies in Web Intelligence, 2(1), 27-33.
} 
mailing list environment, blogs, communities, and public discussions are created for this kind of learning process.

World orientation requires not only the "reception" of information and its networking, but also critical thinking and its classification. It is manifested in practical skills characterizing the construction knowledge on the basis of dynamic changes, the ability of a person not to be afraid of mistakes, network activity and finding the most suitable individual way, as well as mastering technology (Plato \& Cooper, 2009). ${ }^{9}$ However, the other side of connectivistic paradigm is adequately overlooked by the representatives, who do not allow lack of knowledge regarding information structures of networks, unwillingness to be in this network and always to be active in it. It is also emphasized by the philosophical-reflexive definition of the foundations of theory, ${ }^{10}$ which is based on the principles of leadership and cognition (Kahn, 2011). ${ }^{11}$ Focusing on "theory" requires from actors not only learning of technology, but also an understanding of the nature of a learned phenomenon in its particular activity, the principles of the operation of explicit rules and conceptual definitions. An important factor is to eliminate the randomness of adopting new ideas in the sense of a formalism-oriented demagogy. This first "purification" of the formal aspects of a given paradigm shifts the significance of creating new concepts and categories to a specific level of explanation and use not only of concepts, but also meaning in various situations of formulating and interpreting in the process of critical-reflexive understanding. ${ }^{12}$

As an example we can use the basic principles of the Industy 4.0 paradigm, which are based on the fundamental variability of the market and shortening the life of products, digital interconnection as an effort to streamline and innovate various economic models and consumer orientation. These models favor the postulates of generating new economic growth opportunities through sharing and selling the capacities and information, ${ }^{13}$ enriching predictive maintenance and transformed services. Sharing becomes the cornerstone of functioning based on mutual economic relations. ${ }^{14}$ The added value becomes the consumer, who is at the center of all services (made-for-me) and activities, and an equally important element is the emphasis on the environmental dimension and sustainable development. ${ }^{15}$

Concentrating on the individual and using technology will bring us more comfortable and efficient way of living focused on life-enjoyment. These contradictions result in an ideal of the benefit company and facilitating the work of employees, where demanding tasks are lost, making the employee a flexible success coordinator. Social belonging and responsibility to property are transformed into a different form, but it must also be reflected in a human perception of society (Brynjolfsson \& McAfee, 2018). ${ }^{16}$

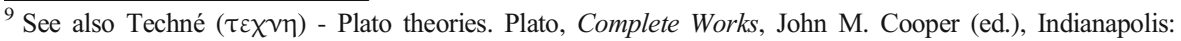
Hackett Publishing Co., 1997.

${ }^{10}$ Perfect answering on basic quetions regarding principle, functions, methods, aims.

${ }^{11}$ See also Eidos, Eidein, episteme. Plato, Complete Works, John M. Cooper (ed.), Indianapolis: Hackett Publishing Co., 1997. Kahn, Charles H., 1996, Plato and the Socratic Dialogue, Cambridge: Cambridge University Press.

12 Avoiding primitive manipulation.

${ }^{13}$ As happens now with mobile operator, online shops, where the customer is forced to fill redundant information having no influence on shopping or services (GDPR, etc.).

${ }^{14}$ Services like carsharing, airbnb, etc.

${ }^{15}$ Zero waste product ideology.

${ }^{16}$ Brynjolfsson, E. (2014). The second machine age: Work, progress, and prosperity in a time of brilliant technologies (First Edition.). New York: W. W. Norton \& Company.
} 
Here, however, any idea of a connectivist approach to education ends, because it does not deal with the dimension of education and its aims as it consideres them to be too idealistic and abstract. Educational sciences have always reflected the particular period, adjusted their educational aims to it and transformed knowledge for life. They never work solely with abstract constructs, language and system of elaborated tautologies about the world and its functioning (Wittgenstein \& Rhees, 1992) ${ }^{17}$ as it might be seemed at first sight. ${ }^{18}$ They inherently differ from the connectivist theory of education because they have their own combination of inspiration (mysticism) and science (methods) (Russell, 1976) ${ }^{19}$ and a definition of ethics that characterises education as transferring and supplying power to man on the road, (contents of sharing) in the "hazy reality" of life. But is a manifestation of mental coding of thought and action. In connection with the ethical dimension, the principle of ethics is often used in the connectivistic ideas. It is understood from a utilitarian point of view, ${ }^{20}$ where the component of evaluating the well-being, the evil and the benefit between the individual and society is emphasized. These subjectivist elements appear in "dusting" and transforming or rewriting concepts and methods of education that have long been used, such as programmed, group and model education, as well as the concepts of inquiry-based teaching, role-playing, simulation of management strategies, elements of game theory, etc.

\section{Searching for values as a mission (im)possible in a value crisis (stimulating or simulating values)}

The Industry 4.0 concept is a consequence of (post)modernity, its outcome and the transformation of society in its development and fluidity (Bauman \& Haffner, 2017; Bauman, 2018). ${ }^{21}$ The fluidity is not only manifested by individualization and globalization, but is also reflected (in the sense of "from Nietze to postmodernity") in the transformation of the power and power elements of privileged social groups in society. The disappearance of "old truths" and systems in post-communist countries in Europe results in "uncertainty" and so-called existential issues in integrating new orders and formalistic views of the future. This view relies on the foundations of the logic of rationality and positivism at the expense of emotion and originality. It is based on a simple causality based on new forms of organization and solutions in the sense of new standards of democratization of all public and archaic ornaments that have worked in the social relations and hierarchy of society.

Priority is given to the well-known archetypes of thinking and insights into society and its representatives. Manifestations of behavior are clearly structured and act as a result of research reports in the form of graphical interpretations of statistical processing

\footnotetext{
${ }^{17}$ Wittgenstein, L. Eine Philosophische Betrachtung, edited by Rush Rhees, in Ludwig Wittgenstein: Schriften, 5, Frankfurt am Main, 1970.

${ }^{18}$ See discussions on outdated school systems and the attempts of their transformation in post-communistic counries.

${ }^{19}$ Bertrand Russell, Mysticism and Logic and Other Essays, New York, London: Longmans, Green \& Co., 1918, In czech version: Logika, věda, filozofie, společnost. Praha 1993.

${ }^{20}$ https://oll.libertyfund.org/titles/mill-the-collected-works-of-john-stuart-mill-volume-i-autobiography-andliterary-essays

${ }^{21}$ Zygmunt Bauman. Liquid modernity. Polity, Cambridge., 2000., Zygmunt Bauman. Das Vertraute unvertraut machen. Ein Gespräch mit Peter Haffner, Hoffmann und Campe, Hamburg 2017.
} 
or taxon omic definitions of the phenomena of the world and the functioning of the world in a quantified measure of quantity. The idea of these tendencies, presented as a reform of Industry 4.0, simplifies the perception of the world on a priori by continuous action and activity (fluidity). ${ }^{22}$ The medium (playground) of these ideas is a virtual and social network world, ${ }^{23}$ which controls form, method and has the power to govern both the rules and content. ${ }^{24}$ This cyclical experience of reality replaces searching for and explaining the goal through content. Status contents are not values, values are transformed into forms of presentation and are not the essence of the system, the essence of the system is the positive and negative preferences as a substitute for economically unlimited time spent in this virtual environment where end users are often faced with a dilemma: I don't know what is the essence and how it works, but I use it just like everyone around me.

The educational streams, that focus mainly on technology, especially education technology as one of the alternative technical education schools, favor the idea of technical thinking. This approach accepts the prerequisites of learning through a model of skills, which results in the sum of competences to perform a particular activity. The second group, based on the ideal of technology, ${ }^{25}$ seeks to describe ideal phenomena and facts (perpetuum mobile, etc.), emphasizes the positivist normative concept while selecting from Wittgenstein only logical-philosophical ideas about the normativeness of scientific knowledge based on research and suppresses the existence of other ideas. It does not deal with the phenomena of transcendence, the phenomena of ethics, the phenomena of human psychological development, as well as the phenomena of language. These terms are only taken up, described and grafted on the theory of connectivism without previous critical-reflexive action. This approach only adhers the importance of a reform and revolution in the industry and economy, and makes them a simplified concept of saving of the world and people, making it a powerful tool for controlling leadership. By highlighting new technologies such as helping society in other areas of human activity and research, it facilitates work activities and reduces the time it takes to achieve results. ${ }^{26}$ It provides the illusion of its indispensability and changes people's minds in terms of dependence ${ }^{27}$ on the technology and its usage. This illusion of 'mini-miracles' is also used in other social sciences such as economics, marketing and PR, which widens and deepens the even greater gap between people in terms of economy, psychological processes, social relationships, ${ }^{28}$ social status and roles. Among scientists, we can commonly notice disputes about the higher status of "their" scientific field, where normativeness and cynicism reflects the "competition" for funding science presented through grant schemes, giving priority to research and focus topics. Combined with the power of political leaders, it is a voluntary and simplified

\footnotetext{
${ }^{22}$ When nothing happens, there's always something that must happen. If they do it, I must do it too.

${ }^{23} \mathrm{FB}$, Instagram, twiter etc.

24 is an example of such an archetype, characters in works of K. Čapek (Novel R.U.R,1984) M. Kundera (Joke, 1967, L'Ignorance, 2000) a V. Havel (The Memorandum, 1968, The Power of the Powerless, 1978, The Garden Party, 1963), as well in Hollywood movies such as Avatar, Matrix or Jurrastic Park.

${ }^{25}$ It is not based on epistema, but on the postulate: The technique that should ideally be when everything is correctly calculated

${ }^{26}$ E.g. robotics or specific software in the field of medicine, geography, mathematics etc.

${ }^{27}$ Who does not use new technologies is weak, vulnerable, backward, oldfashioned.

${ }^{28}$ Ability to control the media, neuroses, psychoses, inferiority and disability complex, or the opposite spectrum, such as dependence on the media or social network.
} 
conception of the world misleaded by the image of an ideal world and promises of a better future and prosperity. Enthusiasm of the power idea (Foucault, 1977) ${ }^{29}$ is hidden behind the widely spread ideal of help that wins the next elections.

This shortsightedness and the visible reactions of the groups in society stems from the unwillingness to participate in the transformation of society with an emphasis on trying to explain the system, norms and laws in terms of their impact in a broad perspective through social sciences and their methodology. ${ }^{30}$ This reluctance is also manifested by the inability to accept the impact of decisions and the inability to adopt moral issues and define their focus through the ethical dimension of decision making (Saha \& Pavan Kumar, 2015). ${ }^{31}$ Value becomes an ideal that replaces a new ideal based on the tautology of the world, which is made up of models. These models resemble the real world, but they are artificially created and programmed with an algorithm according to the idealism of the group that dominates the technological advancement of today. However, they are models using a functional model of the world, a system similar to a system with a rich internal (infra)structure and intrinsic logic and laws that are difficult to understand for their "ordinary" consumers.

\section{What to do with redundant people in industry 5.0, 6.0, ... (emptying of the essence based on supply and demand-based nature)}

According to the definitions, Industry 4.0 is a product of machine-to-machine vision, the result of automation, a fully digitized enterprises (a light-off factory without a human factor) with physical technologies and a human factor functioning only as an output control. Indeed, the policy of globalization, although personally oriented, does not fully count with the elimination of the human factor in the future. A complete replacement with robots and technologies does not mean "erasing" humans as a major element of production and services, but it will require the transformation of human positions in relation to the machine and their cooperation, ${ }^{32}$ where the collaborative robots (cobots) arise. The cooperation is based on ideal images of both elements complementing and eliminating each other's weaknesses. Thus, the role of human to control and supervise remains. It brings challenges for personnel policy and the educational sector in the form of a reform of educational policy at all levels of the educational system. However, not all the people can do a cyber system and programming. The diversification of professions cannot be adapted to the exponential growth of technologies that tend to convince the public through the media about the increasing of the production sphere from primitive form to advanced within a few decades. Till now, no company has been able to easily cope with the image of a fictitious enemy in the form of engaging technology in production processes.

The discussions in the society on this issues have resulted in a neutral outcome, the ravages of many social groups, or other conflicts that have directed the society

\footnotetext{
${ }^{29}$ Foucault, M. Discipline and Punish: The Birth of the Prison, Gallimard,1975.

${ }^{30}$ Methodology is understood here as a science of methods.

${ }^{31}$ Decision component is being used to consolidate power. See more In Saha, S., Kumar, S. P. (2015). Assessing the relationship between participation in decision making, job satisfaction and multiple commitments. OPUS: HR Journal, 6, 18-37.

32 Designation ,stupid machine“
} 
development. Rapidly changing society does not meet with a coexistence of many value worlds and a clear dialogue about the nature of these technologies and experience or their readiness for change. Simple and politically profitable statements give the impression of a great supply from which the client selects only what he/she wants based on his/her demand. This overcomes a fear of tendering and the inability to understand and accept the views of other parties. Reactions in the form of sanctions and "cooling" of economic relations, withdrawing various organizations, political integration groups ${ }^{33}$ or ultimatums of some of the world leading politicians are the result of this way of thinking. The arguments are embedded in the aggressive expression and style of devil's advocates, ${ }^{34}$ savers of the world and defenders of democratic principles. Recent debates on new networks (5Gs) evoke sharing of long social networks statuses and media, where, under the pretext of different opinion, the authors hide their fear resulting from the economic profit and hyper-correct eagerness to explain modern trends. The current disputes, growing into modern forms of conflict do not accentuate the basic economic and social theses of democratization of society and fair play principles. ${ }^{35}$ This ensures media popularity, political score, production of ideas in the form of human desires that reflect the internal uncertainty and insufficient estimating of the situation. Hiding behind the idea of a startup wave, supported by a financially global conglomerate, the representative is unable and unwilling to perceive the views of other groups. It causes internal tension, the emergence and dissemination of unverified media presentations based on purpose-built information. ${ }^{36}$

The classical language of logic that constructs and forms abstract thinking and describes the real world becomes a tragicomic discussion of the impact, power and reform of school systems and assessments. ${ }^{37}$ However, the important essence stays unadressed. The fact that there are more robots that take people's jobs is clear. The principle is based in (pre) transforming professions that require time for training and education. Talent availability, as shown by labor market statistics, ${ }^{38}$ does not exceed its supply. Companies that implement automation, streamline and digitize production often create new types of job positions, define new employee roles and requirements in just in time approach strategies. They accept a not exceeding offer and try to invest in talents. The whole talent process is theoretically characterized as a process of investing in learning and development, ${ }^{39}$ bringing workers to "their" labor market that no longer have employment and possible development in a "home" company, lending and sharing ${ }^{40}$ a community of talents outside the company that we cultivate and move the talents vertically or horizontally across the labor market in different jobs and within one or more companies.

\footnotetext{
33 Brexit in EU

${ }^{34}$ In sence and understunding as a criticm.

${ }^{35}$ The latest global dispute, for example, Huawei and the creation of $5 \mathrm{G}$ networks, which is based on hardware and software infrastructure. The essence of the dispute is about the sovereign status, control mechanisms, limiting or shutting down anything remotely. Less is said about the experience of building infrastructure, the experience, the development and the quality of technology.

${ }^{36}$ Fake news

${ }^{37}$ Easten European reforms of Education, final exams etc.

${ }^{38}$ Infocorp, available at: http://www.infocorp.co.uk/index.html

${ }^{39}$ Benefit offers, flexibility of working hours and workload, cloud computing

${ }^{40}$ Sharing of talents, alternative working models, Outsourcing,
} 


\section{There is somewhere the teacher ("talent" development as a social order for soft-skill education - future directions?)}

In the process of quickly adapting to technological and economic trends, companies require faster selection of talents than in the past. Changes in adaptability in the labor market automatically transform the culture of business models of companies in the area of human resources development, human capital development and the labor market, ${ }^{41}$ thus changing society. This culture is reflected in greater protection and development of company talents, ${ }^{42}$ increasing responsibility ${ }^{43}$ of HR departments of global and national companies and the higher use of internal and external testing tools such as psychometry, performance predictions, skills mapping and potential development in various areas of cognitive and affective personality components.

The second equally important feature is the search for talents on the external market ${ }^{44}$ with regard to the time possibilities of implemented changes in the main content and focus of the work of the company. Nowadays, the whole process of finding and acquiring talents is based on economic benefits. This corporate policy is also changing. A potential employee is aware of his/her qualities and the fact that lack of talents and low unemployment leads to an increase in wages as well as greater employee turnover and requires not only classic benefits ${ }^{45}$ but mainly time flexibility and benefits related to active leisure time, health care for him/herself and also for his/ her family. This phenomenon forces companies to retain core staff and develop a network of recruiting new or external staff (talents) with specific qualifications for the duration of short-term projects.

Outsourcing of some specific activities is solved by subcontracting of turnkey services, short-term, part-time contracts and flexibility of services provided by an external member. This principle forces the HR departments to take on a completely different form and content of the work they have done so far. Great emphasis is placed on work and development of a wide range of activities in the field of human resources and work psychology. Digitization, robotization and automation make the work faster and require not only technical but also personal and social flexibility.

The role of managers and leaders is fundamentally changing and must respond flexibly to changes in the labor market and the disappearance and emergence of professions. This requires lifelong learning in various forms, as well as the development of human potential in the context of education for humanity. The optimization of the production processes puts the manager often in a position to optimize the talent structure and to look for alternative ways of communication and to facilitate the transition of employees to a new role or in certain situations to lead their skills potential in another direction.

However, the efforts to create multi-functional teams with many skills also include a reform of education, not only secondary and vocational, but also university education. These reforms must not only focus on changes in positions, increasing or decreasing of

\footnotetext{
$\overline{{ }^{41} \text { Human resources, human capital. }}$.

42 Talent Development Programs, VOICE (IKEA), potential development etc.

${ }^{43}$ Quality assessment, system of internal and external evaluation, strategic development goals in the medium term and etc.

${ }^{44}$ Head hunting.

${ }^{45}$ Company car and devices, discounts on company products, meals etc.
} 
staff, but mainly on priority education structures. These structures are visible in the concepts of a culture of education and talent creation (qualifications), by changing adaptability to the labor market (abolition of outdated qualifications) and by promoting the ability to learn continuously throughout life. ${ }^{46}$ A synergistic effect of the environment, scope, form and content of education is also a qualitative transformation of teacher education.

Funding IGA project of PDF UPOL: Professional self-concept of the beginning academic workers in relation to their critical thinking. IGA_PdF_2019_033.

Internal grant of PDF UPOL: From subjective implicit theories of education to teaching knowledge. The process of constitution of a cognitive framework sciences education in the national and international context.

Open Access This article is licensed under a Creative Commons Attribution 4.0 International License, which permits use, sharing, adaptation, distribution and reproduction in any medium or format, as long as you give appropriate credit to the original author(s) and the source, provide a link to the Creative Commons licence, and indicate if changes were made. The images or other third party material in this article are included in the article's Creative Commons licence, unless indicated otherwise in a credit line to the material. If material is not included in the article's Creative Commons licence and your intended use is not permitted by statutory regulation or exceeds the permitted use, you will need to obtain permission directly from the copyright holder. To view a copy of this licence, visit http://creativecommons.org/licenses/by/4.0/.

\section{References}

Bauman, Z., \& Haffner, P. (2017). Das Vertraute unvertraut machen: Ein Gespräch mit Peter Haffner. Hamburg: Hoffmann und Campe.

Bauman, Z. (2018). Liquid modernity. Cambridge: Polity Press.

Brynjolfsson, E., and McAfee, A. (2018). The second machine age: Work, progress, and prosperity in a time of brilliant technologies.

Dörner, D. (1989). The logic of failure: Vortrag, gehalten auf d. Tagung "human factors in high-risk situations" d. Royal Society vom 28. - 29. 06. 1989 in London.

Downes, S. (2010). New technology supporting informal learning. Journal of Emerging Technologies in Web Intelligence, 2(1), 27-33.

Eco, U. (2002). Art and beauty in the middle ages. New Haven: Yale University Press.

Foucault, M. (1977). Discipline and punish: The birth of the prision. New York: Vintage Books.

Kahn, C. H. (2011). Plato and the Socratic dialogue. Cambridge: Cambridge University Press http://public. eblib.com/choice/publicfullrecord.aspx?p=4638825.

Plato, \& Cooper, J. M. (2009). Complete works. Indianapolis: Hackett.

Kop, R., Hill, A. (2008). Connectivism: Learning theory of the future or vestige of the past? In "The International Review of Research in Open and Distance Learning", 9(3), ISSN 1492-3831.

Russell, B. (1976). Mysticism and logic and other essays. London: Allen and Unwin. Czech version: Logika, věda, filozofie, společnost. Praha 1993.

Saha, S., and Pavan Kumar, S. (2015). "Assessing the relationship between participation in decision making, job satisfaction and multiple commitments". OPUS: HR Journal, 6(1).

Siemens, G. (2004). Connectivism: A learning theory for the digital age. International Journal of Instructional Technology and Distance Learning. Retrieved on March 12, 2020, from http://www.itdl. org/Journal/Jan 05/article01.htm

Skinner, B. F. (2000). Science and human behavior. Delran: Classics of Medicine Library.

Wittgenstein, L., \& Rhees, R. (1992). Eine philosophische Betrachtung. Pittsboro: InteLex Corp.

Publisher's note Springer Nature remains neutral with regard to jurisdictional claims in published maps and institutional affiliations.

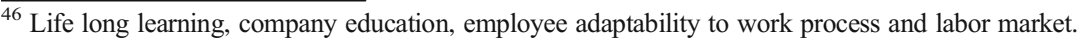

